\title{
Supplier Selection in Dynamic Environment using Analytic Hierarchy Process
}

\author{
Prince Agarwal $^{a}$, Manjari Sahai ${ }^{b}$, Vaibhav Mishra ${ }^{c}$, Monark Bag $^{\text {d,** }}$, Vrijendra Singh $^{c}$ \\ ${ }^{a}$ HCL Technologies, Noida, Uttar Pradesh-201301, India \\ ${ }^{\mathrm{b}}$ Denave India Pvt Ltd, Noida, Uttar Pradesh -201301, India \\ ${ }^{c}$ Indian Institute of Information Technology Allahabad, Uttar Pradesh -211012, India \\ ${ }^{\mathrm{d}}$ Institute of Rural Management Anand, Gujarat-388001, India \\ *Corresponding Author: Monark Bag, E-mail: monarkbag@gmail.com
}

\begin{abstract}
In today's highly competitive business environment, the rapidly changing customer demands and with the advent of enterprise wide information systems, the managers are bound to think beyond the conventional business processes and devise new ways to squeeze out costs and improve the performance without compromising on the quality at the same time. Supplier evaluation and selection is one such area which determines the success of any manufacturing firm. Supplier selection is the problem wherein the company decides which vendor to select to have that strategic and operational advantage of meeting the customers' varying demands and fight the fierce competition. This paper presents a simple model based on Analytic Hierarchy Process (AHP) to help decision makers in supplier evaluation and selection, taking into account the firm's requirements. The article is intended to help new scholars and researchers understand the AHP model and see different facets in first sight.
\end{abstract}

Index Terms - Supplier Selection; Multi-Attribute Decision Making; Analytic Hierarchy Process (AHP); Procurement Strategy; Priority Weights

\section{INTRODUCTION}

In the dynamic and challenging environment, where the product life cycles are increasingly getting short, the changing customer demands, the competition to squeeze out the costs and improve upon the delivery performance it has become extremely important for the manufacturing firms to select the best available resources. In order to match up the pace of the competitors, it has become equally important for the firms to work in close coordination with one another. Supplier Selection is one such area which provides the competitive edge to win the market not only by improving the operational effectiveness but also by the strategic alliance between the firms. The dyadic relationship helps both the firms flourish and prosper even in adverse conditions, reducing the risks involved and bringing out the best possible outcomes out of the existing limited resources. Supplier selection involves various qualitative and quantitative criteria and thus it is a Multi-Criteria Decision Making (MCDM) problem and involves mitigating risk and uncertainty. The decision makers need to analyze and assess the suppliers based on the quantitative and qualitative factors. A firm can decide upon the various criteria based on the type of alignment it is looking with the supplier. The set of evaluation criteria varies whether the firm is looking for strategic partnership or just merely the operational effectiveness (to reduce costs), or whether the relationship between the firms is a short or long term relationship and moreover it also depends on the firm's internal strategy and supply chain strategy (efficiency driven or responsive supply chain). The article discusses the application of AHP for solving the supplier evaluation and selection problem based upon the firm's internal strategy and criteria. This paper would help in giving a quick insight to the AHP and future work in the related area. It is strongly believed that the article would help the practicing scholars get the different facets of AHP.

\section{LITERATURE REVIEW}

In most of the industries, the raw material and product parts have the substantial share in the total manufacturing costs and take the toll rise up to $70 \%$ of the overall manufacturing cost [1]. From a long time, the need of effective and robust selection of supplier has been felt and identified. The supplier selection and evaluation problem is a MCDM problem wherein the firms try to minimize the risk and try to find out the best supplier to meet the uncertainty in business. Supplier selection has become a vital issue in production and operational management literature [2]. An effective supplier helps the firm in minimizing purchasing risk and maximizing the value of both the firm and the supplier. It is the need of the hour to work in close co-ordination and develop the products and services, capable of meeting the demands and customer preferences, using minimum resources. With the change in manufacturing technologies and application of new concept of Just-in-Time (JIT) manufacturing, the supplier selection should focus on bringing the firms more close and establish long term dyadic relationship between them [3]. The researchers have realized the increasing importance of effective supplier selection in incorporating the concept of JIT manufacturing and Total Quality Management $[4,5]$. The supplier selection problem could have been much simpler, it a single criteria e.g. cost could have been used. But single criteria does not yield expected results in this era, thus it becomes very important to identify and consider all the important criteria while evaluating the various suppliers. In the problem, it is essential to determine how far each criteria influences the decision making process. Take a case of Fast Moving Consumer Goods (FMCG) 
products manufacturing company following a responsive supply chain strategy, then the delivery performance may be the most important criteria to rate the suppliers while for best quality goods manufacturing company, quality may be of prime importance while evaluating the suppliers. It depends on the firm whether all the criteria are given equal weights or whether their influence varies with criteria [6]. Supplier selection and evaluation is a MCDM problem in which majority of the researchers focused on the use of quantitative criteria in solving the problem and assign them weights as per the requirements of the firm [7]. There are various conflicting criteria in a MCDM problem and the decision maker needs to analyze the trade-off among the various criteria affecting the decision and assign weights as per the importance [8].

Dickson [9] analyzed and tried to find out the various criteria used by the decision makers in selecting and evaluating the suppliers. The researcher performed an extensive study by sending a questionnaire to two hundred and seventy three managers and purchasing agents. The study revealed that quality was ranked the most important criteria while delivery and performance history stood second and third in the ranking. Weber et al [10] examined the supplier selection literature for the seventy-four articles published since 1966 and attempted to find out the impact of JIT manufacturing on the selection criteria of the decision makers. The researchers identified quality, price, delivery performance, location and production capacity as the most widely used criteria for evaluating supplier's performance. Zhang et al [11] reviewed the literature for the articles published between 1991 and 2003 based upon the study conducted by Weber et al [10]. The researchers reviewed forty-nine articles and found price, quality and delivery performance to be most prominent among the criteria followed by various decision makers. Another review study conducted by Bross and Zhao [12] revealed that cost, quality, relationship, service and organization are among the most valuable supplier evaluation criteria.

Saaty [13] was the one who introduced the Analytical Hierarchy Process (AHP) and presented its applicability in prioritizing the suppliers based on the pre-specified criteria. The AHP proposed by the researchers allowed the decision makers in structuring the complex problem just like a decision tree. The hierarchy consists of generally three levels- goals, criteria and alternatives. Vaidya and Kumar [14] found that AHP is one of the most prominent approaches used by various researchers in solving the supplier selection problem, since its invention. Ghodsypour and O'Brien [1] studied the two conflicting tangible and intangible factors based on AHP, to choose the best supplier. The researchers proposed a model based on AHP integrated with linear programming. Akarte et al [15] proposed a systematic model based on AHP to evaluate and select the best casting quality supplier. The scholars used eighteen different criteria in evaluation the casting suppliers. The criteria were divided into four groups- quality capability, manufacturing capability, product development capability and cost and delivery. Out of the eighteen selected criteria- six were objective types and rest were subjective. Chamodrakas et al [16] proposed an AHP based model to solve the supplier selection problem in electronic marketplace. The proposed model tried to improve upon the information overload effect, generally seen in the electronics industry. The model uses Fuzzy Preference Programming (FPP) along with the AHP for efficiently selecting the best supplier, given the conditions. Tam and Tummala [17] used AHP in evaluation and selection of vendors in the telecommunication industry. The researchers found AHP to be very efficient in evaluating conflicting objectives and finally arrive at a common consensus.

\section{THE AHP MODEL}

Supplier selection includes the qualitative and quantitative evaluation criteria, strategic and operational effectiveness measurement, long term planning and strategy execution to have a competitive advantage over others. One possible scenario in which various suppliers can be evaluated is shown in Fig 1.

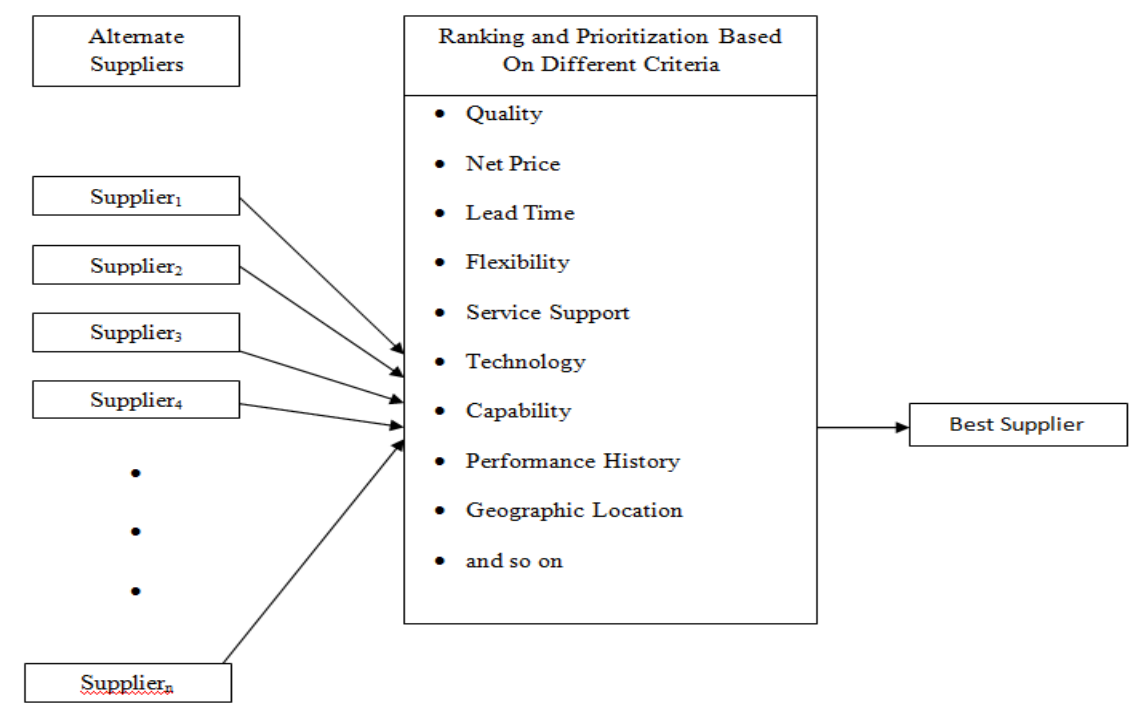

Fig. 1. Scenario of supplier evaluation and selection in manufacturing environment 
AHP is a multi-criteria decision making tool and an Eigen value approach to pair wise comparison. AHP helps the decision makers in modeling the problem in a hierarchical structure. The structure has the main objective or goal at the root node, followed by the criteria at the second level, sub-criteria at the next level and finally the alternatives at the last level. The hierarchy can be generalized to include the criteria, sub-criteria, subsub-criteria and so on. The general hierarchical structure of the AHP is shown in Fig 2.

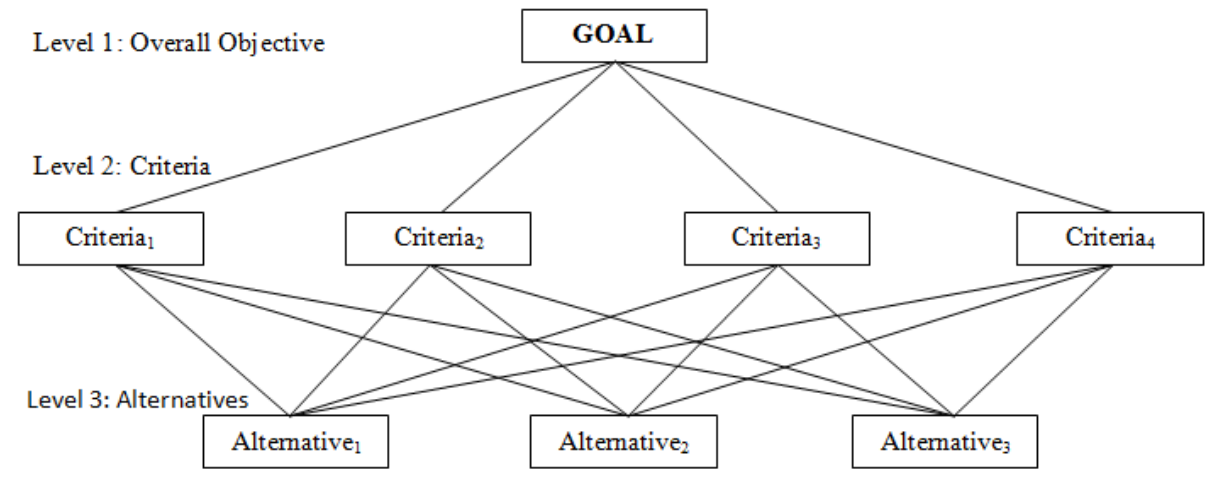

Fig. 2. General hierarchy structure of AHP

The AHP approach helps in calibrating the scale for representing qualitative dimensions in quantitative terms and hence helps in maintaining consistency among the various parameters used for evaluation. The AHP model proposed by Saaty [18] uses a nine point scale. Saaty [18] also used the same nice point scale to assign the weights. The scale values and the judgments are shown in Table 1.

Table 1. Scale values for pair wise comparison

\begin{tabular}{|c|c|}
\hline Verbal Judgment or Preference & Rating Level \\
\hline Extremely Preferred & 9 \\
\hline Very, Very Strong & 8 \\
\hline Very Strongly Preferred & 7 \\
\hline Strong Plus & 6 \\
\hline Strongly Preferred & 5 \\
\hline Moderate Plus & 4 \\
\hline Moderately Preferred & 3 \\
\hline Weak or Slight & 2 \\
\hline Equally Preferred & 1 \\
\hline
\end{tabular}

Initially each criterion is assigned a priority weight based on its importance in evaluation of suppliers. The priority weight is assigned depending on the commodity type, its lead time, the type of supply chain strategy of the firm, the criticality in terms of impact of variability on the business performance and so on. Then after, all the entities at each level of AHP model are compared pair wise to get the pair wise judgments, to find out the relative importance of various criteria and sub-criteria. Therefore, in case of $\mathrm{n}$ distinguished criteria at a level, we have $n(n-1) / 2$ compared values. Fig 3 shows the pair wise comparison in case of four criteria at any level of AHP.

The results of the pair wise comparison are gathered in the pair wise matrix structure, wherein each criterion is compared to rest of the criteria at the same level. A sample pair wise comparison matrix is shown in table 2 .

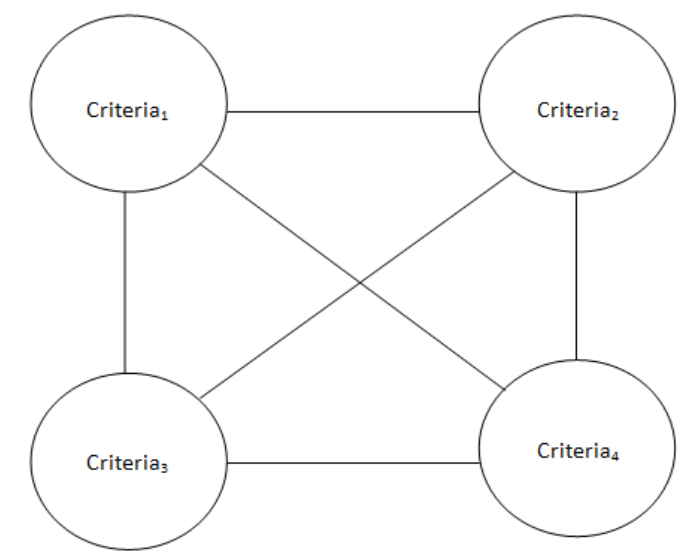

Fig. 3. Pair wise comparison in case of four criteria at a level

Table 2. A sample pair wise comparison matrix

\begin{tabular}{|c|c|c|c|c|c|}
\hline Selection Criteria & $\mathrm{C}_{1}$ & $\mathrm{C}_{2}$ & $\mathrm{C}_{3}$ & $\mathrm{C}_{4}$ & $\mathrm{C}_{5}$ \\
\hline Cost $\left(\mathrm{C}_{1}\right)$ & 1 & 2 & 4 & 5 & 3 \\
\hline Quality $\left(\mathrm{C}_{2}\right)$ & $1 / 2$ & 1 & 3 & 4 & 4 \\
\hline Delivery $\left(\mathrm{C}_{3}\right)$ & $1 / 4$ & $1 / 3$ & 1 & 3 & 4 \\
\hline Technology $\left(\mathrm{C}_{4}\right)$ & $1 / 5$ & $1 / 4$ & $1 / 3$ & 1 & 3 \\
\hline Service Support $\left(\mathrm{C}_{5}\right)$ & $1 / 3$ & $1 / 4$ & $1 / 4$ & $1 / 3$ & 1 \\
\hline
\end{tabular}

Therefore, a vendor having good performance on cost is slightly preferred to the one on quality (a value of 2), which is strongly preferred compared to the delivery and technology. Similarly, good performance in quality is moderately preferred over consistent delivery performance, and strongly more important than the one using the latest technology and having good service support. Only the elements above the main diagonal of the matrix needs to be filled up, while the lower triangle can be calculated taking the inverse cell values. The diagonal elements hold the value of 1 as both the criteria compared are the same and thus are equally important.

Once the pair wise comparison matrix has been filled, next task is to compute the priority vector (weighting) for 
the criteria. In order to find the vector, the Eigen values need to be computed and thus the column wise total is calculated. On order to normalize the values on the scale of 1 , each entry of the column is divided by the corresponding column total and finally the row wise sum id calculated. Now, to find out the actual weight of any criterion its row total is divided by the number of criteria to arrive at the average weight out of 1 , as shown in table 3.

Table 3. Normalized pair wise matrix and calculated priority weights

\begin{tabular}{|c|c|c|c|c|c|c|c|}
\hline Criteria & $\mathrm{C}_{1}$ & $\mathrm{C}_{2}$ & $\mathrm{C}_{3}$ & $\mathrm{C}_{4}$ & $\mathrm{C}_{5}$ & ROW TOTAL & AVERAGE \\
\hline $\mathrm{C}_{1}$ & 0.438596 & 0.522193 & 0.4662 & 0.375094 & 0.2 & 2.002083942 & 0.400 \\
\hline $\mathrm{C}_{2}$ & 0.219298 & 0.261097 & 0.34965 & 0.300075 & 0.266667 & 1.396786886 & 0.279 \\
\hline $\mathrm{C}_{3}$ & 0.109649 & 0.086162 & 0.11655 & 0.225056 & 0.266667 & 0.80408405 & 0.160 \\
\hline $\mathrm{C}_{4}$ & 0.087719 & 0.065274 & 0.038462 & 0.075019 & 0.2 & 0.466473743 & 0.094 \\
\hline $\mathrm{C}_{5}$ & 0.144737 & 0.065274 & 0.029138 & 0.024756 & 0.066667 & 0.330571378 & 0.067 \\
\hline TOTAL & 1 & 1 & 1 & 1 & 1 & & \\
\hline
\end{tabular}

In the table, it is evident that the criteria $C_{1}(0.4)$ is valued the most by the decision makers and thus is given the highest weight or priority in evaluating the supplier followed by $\mathrm{C}_{2}(0.279), \mathrm{C}_{3}(0.16), \mathrm{C}_{4}(0.093)$ and $\mathrm{C}_{5}$ (0.066). Once the priority weights have been computed, the consistency ratio is calculated to check for the inconsistency in the ranking done by the decision makers in selecting the criteria. This is another important thing in AHP which eliminates the inconsistencies in the weighting of the criteria and differentiates it from rest of the methods. According to Saaty [18], the consistency ratio $(\mathrm{CR})$ of 0.10 is acceptable. If the $\mathrm{CR}$ value thus calculated, falls short than 0.10 then the weight results are considered valid and consistent. Otherwise, the pair wise matrix results are considered inconsistent and therefore are not used for further analysis. To computer the CR, we need to calculate the consistency index (CI) using the relation-

$$
C I=\left(\lambda_{\max }-n\right) /(n-1)
$$

Where $n$ is the size of pair-wise comparison matrix and $\lambda_{\max }$ is calculated by multiplying the pair wise comparison matrix (Table 2) with the average weights of the criteria calculated in Table 3 and then dividing the thus computer values with the average values of the criteria. The average of the calculated values is then taken to get $\lambda_{\max }$ and this gives us the CI using the above relation. The random consistency index $\mathrm{RI}=1.10$ for $n=5$. On calculation we arrive at $\mathrm{CR}=0.1$ which is just at the boundary value and we accept the above criteria. Now when the final weights have been calculated, the different sub-criteria and alternatives can be easily evaluated.

\section{ILLUSTRATIVE EXAMPLE}

Let us now consider a hypothetical firm dealing in manufacturing of baby toys, which needs to evaluate its suppliers based on four factors. The four criteria being used are cost (C), operations (O), delivery (D) and flexibility $(F)$. The four factors used in the numerical example are independent, as per the requirements of the Saaty [18]. There are three suppliers- A, B and C out of which the firm wants to select the best supplier. The AHP model of the above problem is shown in Fig 4. In the structure, the overall objective is to select the best supplier for supplying the toy parts to the firm and this lies at level 1.

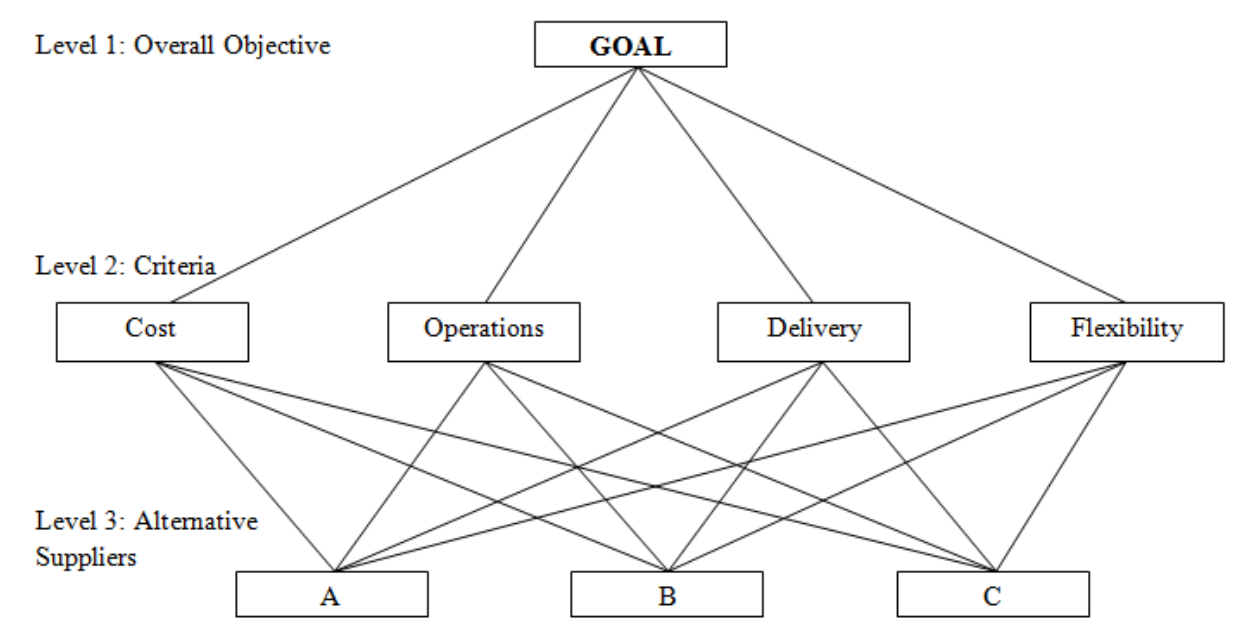

Fig. 4. AHP hierarchy structure for the firm 
Next level consists of the four evaluation criteria followed by the alternate suppliers on level 3 . The main objective of the model is to evaluate and select the best supplier out of them. First of all, the pair-wise comparison matrix has to be prepared. As shown in table 4 for the firm, the operational support is slightly more important than the expenses or price while cost is far more important than the delivery (rating $=5$ ). The firm observes that the operational support is considerably more important as compared to delivery performance (rating =5) and flexibility is considerably more important than delivery performance (rating $=5$ ).
Table 4. Pair wise comparison matrix for the firm

\begin{tabular}{|c|c|c|c|c|}
\hline Selection Criteria & C & O & D & F \\
\hline Cost (C) & 1 & $1 / 3$ & 5 & 1 \\
\hline Operations (O) & 3 & 1 & 4 & 1 \\
\hline Delivery (D) & $1 / 5$ & $1 / 4$ & 1 & $1 / 4$ \\
\hline Flexibility (F) & 1 & 1 & 4 & 1 \\
\hline
\end{tabular}

Now once the pair-wise comparison matrix has been prepared, the next task is to normalize the above matrix to find out the criterion weights on a scale of 1 or $100 \%$. In order to get the priority weights, the column wise total is calculated and each column element is divided by the corresponding column's total as shown in table 5 .

Table 5. Normalized pair-wise comparison matrix and priority weights

\begin{tabular}{|c|c|c|c|c|c|c|}
\hline Criteria & C & O & D & F & ROW TOTAL & AVERAGE \\
\hline Cost (C) & 0.192 & 0.128 & 0.357 & 0.308 & 0.985 & 0.246 \\
\hline Operations (O) & 0.577 & 0.388 & 0.286 & 0.308 & 1.558 & 0.389 \\
\hline Delivery (D) & 0.038 & 0.097 & 0.071 & 0.077 & 0.284 & 0.071 \\
\hline Flexibility (F) & 0.192 & 0.388 & 0.286 & 0.308 & 1.173 & 0.293 \\
\hline TOTAL & 1 & 1 & 1 & 1 & & 1 \\
\hline
\end{tabular}

Thus for the firm operational support $(0.389)$ is the highest priority followed by Flexibility (0.293), Cost (0.246) and lastly Delivery Performance (0.071). The Eigen vector thus calculated $(0.246,0.389,0.071,0.293)$ is shown in last column of table 5 . The CR calculated is 0.071 which is less than the upper cap of 0.1 , thus the matrix comparison is consistent and acceptable. Now this can be seen from the above comparison matrix that the most preferred criteria to evaluate the suppliers is to have consistent and remarkable operational support. The ranking of evaluation criteria is shown in table 6 .

Table 6. Ranking of criteria

\begin{tabular}{|c|c|c|}
\hline Rank & Criteria & Global Weight \\
\hline 1 & Operations & 0.389 \\
\hline 2 & Flexibility & 0.293 \\
\hline 3 & Cost & 0.246 \\
\hline 4 & Delivery & 0.071 \\
\hline
\end{tabular}

The next step after the priority weighting of the criteria is to evaluate various suppliers on the basis of each criterion:

\section{A. Cost}

On the basis of the cost or expenses to the firm, the three suppliers are assigned ranks as shown in table 7.

Table 7. Pair-wise comparison matrix of suppliers A, B and C based on expenditure

\begin{tabular}{|c|c|c|c|}
\hline COST & A & B & C \\
\hline $\mathbf{A}$ & 1 & 5 & 9 \\
\hline $\mathbf{B}$ & $1 / 5$ & 1 & 3 \\
\hline $\mathbf{C}$ & $1 / 9$ & $1 / 3$ & 1 \\
\hline
\end{tabular}
terms of cost and is extremely preferred over $\mathrm{C}$, when the firm takes only expenses into account. Similarly, B is moderately preferred over $\mathrm{C}$. Thus it could be interpreted that the supplier $\mathrm{C}$ is least preferred out of the three, when the decision is solely based on the costs. The Eigen Vector calculated for this matrix is $(0.74,0.18,0.07)$ and shows that the supplier A is seemingly the best out of the three in terms of expenses. The CR calculated is 0.037 (less than upper cap of 0.1 ) and thus the results are consistent and acceptable.

\section{B. Operations}

On the basis of the operational support, the three suppliers are assigned ranks by the firm as shown in table 8 given below-

Table 8. Pair-wise comparison matrix of suppliers A, B and C based on operational support

\begin{tabular}{|c|c|c|c|}
\hline OPERATIONS & A & B & C \\
\hline A & 1 & 1 & 5 \\
\hline B & 1 & 1 & 3 \\
\hline C & $1 / 5$ & $1 / 3$ & 1 \\
\hline
\end{tabular}

The above table shows that $\mathrm{A}$ is strongly preferred than $\mathrm{C}$ in terms of operations support while B is moderately preferred over $\mathrm{C}$, when the firm takes only operations support into account. The Eigen Vector calculated for this matrix is $(0.48,0.40,0.11)$ and shows that the supplier A is seemingly the best out of the three in terms of operations support. The CR calculated is 0.037 (less than upper cap of 0.1 ) and thus the results are consistent and acceptable. 


\section{Delivery Performance}

On the basis of the delivery performance, the three suppliers are assigned ranks by the firm as shown in table 9 given below-

Table 9. Pair-wise comparison matrix of suppliers A, B and C based on delivery performance

\begin{tabular}{|c|c|c|c|}
\hline DELIVERY & A & B & C \\
\hline $\mathbf{A}$ & 1 & $1 / 3$ & $1 / 9$ \\
\hline $\mathbf{B}$ & 3 & 1 & $1 / 3$ \\
\hline $\mathbf{C}$ & 9 & 3 & 1 \\
\hline
\end{tabular}

The above table shows that $\mathrm{B}$ is moderately preferred over $\mathrm{A}$ in terms of delivery performance while $\mathrm{C}$ is extremely preferred over $\mathrm{A}$ and moderately preferred over B, when the firm takes only delivery performance into account. The Eigen Vector calculated for this matrix is $(0.07,0.23,0.69)$ and shows that the supplier $\mathrm{C}$ is seemingly the best out of the three in terms of delivery performance. The CR calculated is 0 (perfect consistency) and thus the results are consistent and acceptable.

\section{Flexibility}

On the basis of the flexibility in business or adaptability, the three suppliers are assigned ranks by the firm as shown in table 10 given below-

Table 10. Pair-wise comparison matrix of suppliers A, B and C based on flexibility

\begin{tabular}{|c|c|c|c|}
\hline FLEXIBILITY & A & B & C \\
\hline A & 1 & $1 / 9$ & $1 / 5$ \\
\hline B & 9 & 1 & 2 \\
\hline C & 5 & $1 / 2$ & 1 \\
\hline
\end{tabular}

The above table shows that $\mathrm{B}$ is extremely preferred over $\mathrm{A}$ in terms of flexibility and slightly preferred over C. On the other hand, $\mathrm{C}$ is strongly preferred over A, when the firm takes only delivery performance into account. The Eigen Vector calculated for this matrix is $(0.06,0.61,0.31)$ and shows that the supplier $\mathrm{B}$ is seemingly the best out of the three in terms of flexibility. The CR calculated is 0 (perfect consistency) and thus the results are consistent and acceptable.

Table 11. Matrix of Eigen Vectors for A, B and C.

\begin{tabular}{|c|c|c|c|c|}
\hline FLEXIBILITY & Cost $(\mathbf{C})$ & Operations $(\mathbf{O})$ & Delivery (D) & Flexibility (F) \\
\hline Supplier A & 0.74 & 0.48 & 0.07 & 0.06 \\
\hline Supplier B & 0.18 & 0.40 & 0.23 & 0.61 \\
\hline Supplier C & 0.07 & 0.11 & 0.69 & 0.31 \\
\hline
\end{tabular}

Now when the suppliers have been evaluated taking into account one criteria at a time, so the overall matrix showing the Eigen Values of each supplier for different criteria is given below in table 11 .

The matrix shown in table 11 shows the performance of various alternative suppliers in terms of various criteria. From the first sight, one can easily interpret that supplier $\mathrm{A}$ is far better than $\mathrm{B}$ and $\mathrm{C}$ in terms of $\mathrm{C}$ and $\mathrm{O}$, supplier $\mathrm{B}$ is the best in terms of flexibility and lastly supplier $\mathrm{C}$ is the best when one considers the delivery performance. But before making the final conclusion it is important to determine the performance of the suppliers as per the requirements of the firm. Thus, for some firm which focuses more on cost and operations support, the supplier A may be the best but not for all the firms. Similarly, the firm whose main evaluation criterion is delivery performance would opt for supplier $\mathrm{C}$ as compared to the rest two. To get the maximum value out of the money, the firm should select that supplier which performs best as per the firm's requirements. Thus, to make the final judgment the above values need to be multiplied with the Eigen values $(0.246,0.389,0.071,0.293)$ of the four criteria calculated in table 5. Finally after matching the firm's requirements with the supplier's capabilities it is found that supplier B is the best supplier for the firm with the score of 0.395 followed by supplier A at 0.391 . Supplier C remained on the last position with net score of 0.199. Hence, supplier B is the best supplier for the firm.

\section{CONCLUSIONS}

Supplier evaluation and selection is emerging as a sword for the firms in achieving a comfortable position in the market and having a competitive edge over the competitors. Effective supplier selection has helped the big organizations in reducing the risks associated with the performance and in dealing with market uncertainties. The AHP provides a structured approach to model the complex decision making problem of supplier selection and hence helps in reduction of complexity of the situation. The consistency ratio eliminated the possible inconsistencies and help in priority ranking of criteria. The model proposed has been verified with help of an example of a hypothetical firm dealing in toy manufacturing. The system is capable of handling complex problems involving various criteria, sub-criteria, sub-sub-criteria and can facilitate decision makers in selecting the best suited supplier among the numerous suppliers.

\section{REFERENCES}

[1] Ghodsypour S. H., and O'Brien C., "A decision support system for supplier selection using an integrated analytical hierarchy process and linear programming", International Journal of Production Economics, Vol. 56-57, pp 199-212, 1998 
[2] Motwani J., and Youssef M., "Supplier selection in developing countries: a model development", Integrated Manufacturing Systems, Vol. 10, No. 3, pp 154-162, 1999.

[3] Li C.C., and Fun Y.P., "A new measure for supplier performance evaluation", IIE Transactions, Vol. 29, No. 9, pp 753-758, 1997.

[4] Petroni A., "Vendor selection using principal component analysis", The Journal of Supply Chain Management, Vol. 36, No.2, pp 63-69, 2000.

[5] Liu F.H.F., and Hai. H.L., "The voting analytic hierarchy process method for selecting supplier", International Journal of Production Economics, Vol. 97, No. 3, pp 308317, 2005.

[6] Yahya S., and Kingsman B., "Vendor rating for an entrepreneur development programme: a case study using the analytic hierarchy process method", Journal of the Operational Research Society, Vol. 50, No. 9, pp 916-930, 1999

[7] Chen-Tung C., Ching-Torng L., and Huanget S.F., “ A fuzzy approach for supplier evaluation and selection in supply chain management", International Journal of Production Economics, Vol.102, No. 2, pp 289-301, 2006.

[8] Dulmin R., and Mininno V., "Supplier selection using a multi-criteria decision aid method", Journal of Purchasing and Supply Management, Vol. 9, No. 4, pp 177-187, 2003.

[9] Dickson G.W., "An analysis of vendor selection systems and decisions", Journal of Purchasing, Vol. 2, No. 1, pp 517, 1966.

[10] Weber C.A., Current J.R., and Benton W.C., "Vendor selection criteria and methods", European Journal of Operational Research, Vol. 50, No.1, pp 2-18, 1991.

[11] Zhang Z., Lei J., Cao N., To K., and Ng K., "Evolution of Supplier Selection Criteria and Methods", European Journal of Operational Research, Vol. 4, No.1, pp 335-342, 2003.

[12] Bross M. E., and Zhao G., "Supplier selection process in emerging markets - The case study of Volvo Bus Corporation in China" Master Thesis. School of Economics and Commercial Law. Göteborg University, 2005.

[13] Saaty T.L. "Decision making with the analytic hierarchy process", International Journal of Services Sciences, Vol. 1, No. 1, pp 83-98, 2008.

[14] Vaidya O.S., and Kumar S., "Analytic hierarchy process: An overview of applications" European Journal of Operational Research, Vol. 169, No.1, pp 1-29, 2006.

[15] Akarte M.M., Surendra N.V., Ravi B., and Rangaraj N., "Web based casting supplier evaluation using analytical hierarchy process", Journal of the Operational Research Society, Vol. 52, No. 5, pp 511-522, 2001.

[16] Chamodrakas I., Batis D., and Martakos D., "Supplier selection in electronic marketplaces using satisficing and fuzzy AHP”, Expert Systems with Applications, Vol. 37, No.1, pp 490-498, 2010.

[17] Tam M.C.Y., and Tummala V.M.R., "An Application of the AHP in vendor selection of a telecommunications system" Omega, Vol. 29, No. 2, pp 171-182, 2001.

[18] Saaty T, "The Analytic Hierarchy Process", N. Y. McGraw-Hill, 1980.

\section{Authors' Profiles}

Prince Agarwal is an assistant manager at HCL Technologies. $\mathrm{He}$ did his MBA (IT) from Indian Institute of Information Technology Allahabad and B.Tech (Information Technology) from Uttar Pradesh Technical University, India. He received
Institute gold medal from IIIT Allahabad for the highest performance during his MBA (IT). His areas of interest include IT service management, business analytics, project management, transition management and logistics.

Manjari Sahai is a SMB Manager at Denave India Pvt. Ltd, Noida, India. Prior to joining Deneve India, She was worked with HCL Infosystems Ltd. She did her MBA (IT) from Indian Institute of Information Technology Allahabad and B.Tech (Electronics Engineering) from Uttar Pradesh Technical University, India. Her areas of expertise include business development, partner management, IT risk management and business continuity planning.

Vaibhav Mishra is pursuing $\mathrm{PhD}$ from Indian Institute of Information Technology Allahabad. He did his MBA (IT) from Indian Institute of Information Technology Allahabad and B.Tech (Computer Science and Engineering) from Uttar Pradesh Technical University, India. His areas of interest include Internet banking, IT service management, supply chain management, quality management and six sigma.

Monark Bag is an Assistant Professor of Production and Operations management area at Institute of Rural Management Anand (IRMA). Prior to joining IRMA, he was a faculty member at IMT Ghaziabad and Indian Institute of Information Technology Allahabad. He holds a B.Tech (Computer Science and Engineering), MBA (Information Technology Management) and $\mathrm{PhD}$ (Engineering). He was received "UGC Meritorious Fellowship" for his doctoral research entitled "An Expert System for Control Chart Pattern Recognition." His research interest includes expert system, control chart pattern recognition, quality control, optimization techniques and intrusion detection systems. He has published many papers in reputed journals, conferences and book chapters. He is a regular reviewer of various reputed international journals like Computers and Industrial Engineering (Elsevier), European Journal of Operational Research (Elsevier), Neurocomputing (Elsevier), Decision Science (Wiley), Journal of the Operational Research Society UK (Palgrave Macmillan), International Journal of Rural Management (Sage) etc.

Vrijendra Singh is an Assistant Professor at Indian Institute of Information Technology, Allahabad. Prior to joining IIITA, he was a senior project associate at Indian Institute of Technology, Kanpur. He holds $\mathrm{PhD}$ in Computer Science (Independent Component Analysis and Blind Source Separation applications to Signal Processing and Artificial Neural Networks). He is highly engaged in teaching and research. His research interest includes information security and forensics, artificial neural networks, machine learning, computational neuroscience, enterprise resource planning, data mining and digital signal processing. He has published many papers in reputed journals, conferences and book chapters. 